\title{
UniCEUB: alfabetização e letramento na EJA
}

\author{
UniCEUB: literacy education and literacy in \\ youth and adult
}

Ana Regina Melo Salviano' Maria das Dores Brigagão ${ }^{2}$ Norma D' Albuquerque Augusto ${ }^{3}$
Data de submissão: 02-05-2014

Data de aprovação: 23-07-2014

1 Professora do curso de Alfabetização e letramento na EJA - UniCEUB, Mestrado em educação pela UnB 3

2 Professora do curso de Alfabetização e letramento na EJA - UniCEUB, Especialização em Matemática pela UnB

3 Professora Supervisora de Estágio do UniCEUB, Responsável pelo Projeto Alfabetização e Letramento na EJA e Mestre em Gerontologia pela UCB

\section{Resumo}

O projeto UniCEUB - Alfabetização e Letramento na EJA tem o compromisso com a formação integral do ser e o resgate de valores essenciais à vida humana, valorizando a inclusão e a responsabilidade social. Vinculado à Assessoria de Extensão e Integração Comunitária da IES, tem como objetivo participar do enfrentamento da inclusão social e da sustentabilidade do país no que se refere a alfabetização e letramento da população jovem e adulta. Como metodologia, escolhemos o método independente de trabalho que consiste em realizar tarefas dirigidas e orientadas pelo professor capacitador para que os alunos aprofundem conhecimentos.

Palavras-chave: Alfabetização. Letramento. Inclusão social. Construção do conhecimento.

\section{Abstract}

The UniCEUB - Youth and Adults Literacy project is committed to the integral formation of the citizen and the rescue of essential values to human life, valuing social inclusion and responsibility. Linked to the Extension and Community Integration Office of the institution it aims to take part in dealing with social inclusion and sustainability of the country with regard to literate youth and adult illiterate population. The methodology chosen was the independent working method that is to perform directed and guided tasks by the teacher in order to deepen the student's knowledge.

Keywords: Literacy. Social inclusion. Construction of knowledge. 
O presente artigo apresenta algumas reflexões a respeito da formação e do preparo dos agentes alfabetizadores para a educação de jovens e adultos.

Este trabalho é fruto de estudos e pesquisas, elaborado pela equipe pedagógica do Projeto Institucional de Extensão - UniCEUB: Alfabetização e Letramento na $E J A$, que propõe capacitar alfabetizadores, selecionados entre os acadêmicos da IES e integrantes da comunidade externa para atuarem nos locais do Distrito Federal onde existir essa necessidade.

Preparando e construindo a prática pedagógica e a metodologia organizada para essa capacitação, a equipe pedagógica estrutura essa proposta de formação de alfabetizadores com o objetivo de atender aos temas organizados para os encontros. Assim, as aulas são preparadas levando em consideração o conhecimento acumulado no campo da alfabetização, dos construtos pedagógicos adquiridos durante o processo e da integração dos participantes numa perspectiva dialética com ênfase na troca de saberes e experiência e na construção das práticas pedagógicas das diferentes metodologias. A relação afetiva permeia o processo de aquisição de habilidades para o domínio da leitura e da escrita de jovens e adultos.

Para atingir os fins à que se destina, essa capacitação dos agentes alfabetizadores é organizada em 70 horas, distribuídas em 35 aulas, com 2 horas de duração. Os momentos presenciais incluem aulas teóricas, atividades práticas em grupo e individuais, oficinas para confecção de materiais, simulações de situações de sala de aula e dinâmicas de grupo interpessoais, intragrupais e intergrupais.

Como limitações dessa formação, destacam-se os seguintes aspectos relativos aos alfabetizadores:

- candidatos que possuem magistério e não são preparados para alfabetizar;

- candidatos que possuem magistério, são preparados para alfabetizar e não atuam;

- leigos (pessoas que não possuem conhecimento aprofundado sobre determinada área).

- alunos do $3^{\circ}$ ano do ensino médio e participantes de ONGs.

O projeto UniCEUB: Alfabetização e Letramento na EJA enfatiza a preocupação dessa Instituição de Ensino Superior na formação integral do ser e no resgate de valores essenciais à vida humana para a construção de uma sociedade mais democrática. Portanto, essa formação de agentes alfabetizadores insere-se como atividade da Assessoria de Extensão e Integração Comunitária do UniCEUB, com o objetivo de participar, de maneira efetiva, do enfrentamento da questão da inclusão social, colaborando para alfabetizar aquela parcela da população que ainda não se beneficiou dessa conquista.

Dessa forma, a participação voluntária do corpo discente e da comunidade representa esforço conjunto para a consecução dos quatro pilares da educação: aprender a conhecer, aprender a fazer, aprender a viver juntos e aprender a ser (DELORS, 2001, grifo do autor).

$\mathrm{O}$ aprender a conhecer refere-se à aquisição de competências destinadas à compreensão que incluem o domínio do conhecimento, das relações interpessoais e, assim, constroem conhecimentos, exercitam o pensamento, a atenção e a memória, selecionando as informações efetivas para o processo de ensino e aprendizagem ocorrer de forma contextualizada.

Quanto ao aprender a fazer, pode ser compreendido como um aspecto que desperta e estimula a criatividade à descoberta construtiva do trabalho, da participação e da importância da comunicação entre o homem e a sociedade.

No aprender a viver juntos, destaca-se a importância de conviver com os outros em espaço estimulador de projetos cooperativos que objetivam o desenvolvimento solidário.

Na concepção do aprender a ser, todo ser humano deve estar preparado a elaborar pensamentos críticos e autônomos, capazes de reformular juízos de valor próprios, de modo a poder decidir por si mesmo como agir em diferentes circunstâncias da vida.

Dessa forma o Programa Alfabetização e Letramento (BRASIL, 2004, p. 23) da Escola Aberta enfatiza e destaca a educação ao longo da vida como:

[...] uma necessidade inerente ao paradigma educacional emergente como condição para(re) construção cotidiana do ser humano em todas as suas dimensões. A pessoa aprende desde o seu nascimento durante toda a sua vida e assim, a escola deve possibilitar ao educando desenvolver habilidades e competências de aprendizagem continuada [...].

Nesse sentido, a preparação pedagógica de alfabetizadores assume o caráter de ação essencial para que a transformação social, política, a questão da inclusão e do resgate da cidadania se efetivem. Por outro lado, contribui para a melhoria da qualidade de vida, para a realização pessoal dos participantes e para o desenvolvi- 
mento de maior solidariedade entre as pessoas, conforme apontado na Declaração Universal sobre o Voluntariado (IAVE, 1990).

Desse modo é importante salientar os objetivos pretendidos e resultados alcançados pela equipe pedagógica durante o decorrer da formação que é o de oferecer a capacitação de estudantes do UniCEUB e comunidade externa, propiciando conhecimentos gerais, metodologias apropriadas à educação de jovens e adultos, atividades manuais geradoras de renda, dentre outras.

Com referência aos objetivos específicos, podemos citar: conhecer as características básicas dos jovens e adultos; habilitar e qualificar o professor de jovens e adultos; caracterizar a realidade da educação de jovens e adultos; contextualizar letramento e alfabetização; apresentar e caracterizar métodos e processos de alfabetização: sintéticos, analíticos e ecléticos ou mistos; evidenciar os pressupostos e os processos metodológicos da pedagogia de Paulo Freire, quanto à aplicabilidade; identificar conhecimentos básicos sobre a psicogênese da alfabetização e seus procedimentos metodológicos; situar e caracterizar a numerização como elemento constituinte do processo de alfabetização e seus respectivos procedimentos metodológicos; identificar as etapas do planejamento; organizar e sistematizar oficina pedagógica visando à elaboração e à produção de material didático pedagógico para construir ambiente alfabetizador; identificar as habilidades e competências manuais, culinárias, criativas; aplicando e incentivando o desenvolvimento de técnicas que contribuam coma geração da renda familiar e, ainda, orientar e preparar o trabalho pedagógico do alfabetizador.

Tendo como base os objetivos e os referenciais teóricos traçados pelos estudiosos sobre alfabetização e letramento, passamos a descrever o caminho metodológico e o uso de recursos didáticos utilizados no decorrer do processo ensino-aprendizagem.

A capacitação dos alfabetizadores tem como princípio metodológico a construção coletiva de conhecimentos, a vivência e o planejamento das intervenções didáticas. Ao alfabetizador pressupõe-se o trabalho de organizar a instrumentalização teórico-prática para assegurar os modos de articular o processo de ensino e aprendizagem e ainda, recriar a prática de ensino própria, de forma a torná-la reflexiva e crítica.

Portanto, é importante esclarecer a ação do agente alfabetizador em sua sala de aula e sua prática pedagógica porque isso exige conhecimento teórico, assim como habilidades e recursos que transcendem o saber e o fazer em situações reais. Para Sacristán (1997, p. 35-41), a prática pedagógica pode ser compreendida como: "sem compreender o que faz, a prática pedagógica é mera reprodução de hábitos existentes ou respostas a demandas externas. Se um projeto se concretiza em Educação é porque os docentes o fazem seu de alguma maneira, interpretando-o e adaptando-o".

Neste sentido, parece existir uma crença generalizada de que o trabalho do docente é consequência natural do saber. Entende-se, portanto, que as atividades devem ser desenvolvidas por meio de trabalhos participativos que procurem estimular o desenvolvimento do conteúdo programático em situações de troca de experiências. Para isso, os encontros de capacitação foram organizados em forma de aulas expositivas dialogadas, leitura e discussão de textos, oficinas pedagógicas e diversificadas técnicas de grupo. Para que haja maior integração e vivência na construção das ideias dos textos estudados, a equipe pedagógica utiliza retroprojetor, sistema multimídia, flipchart, cartazes, vídeos, quadro de giz, entre outros recursos.

Outro procedimento metodológico é o caderno-volante, que é fornecido pelo professor para que sejam realizados os registros coletivos da turma. Cada dia, um (a) aluno (a) é escolhido (a), logo no início dos trabalhos, para anotar o que foi interessante, o que chamou atenção, as dúvidas das atividades desenvolvidas, o destaque da aprendizagem de algum colega, um elogio e outros comentários que se fizerem necessários. O caderno-volante ajudará o (a) futuro (a) professor (a) a ter referencial do que foi desenvolvido no decorrer da aula, a problematizar, junto aos colegas, o que foi estudado e discutido em sala e, ao mesmo tempo, terá visão da rotina do contexto da sala de aula, podendo pesquisar o que foi ministrado a partir da leitura diária desse material.

A necessidade de ampliar o conhecimento a respeito da área de alfabetização motiva a inserção de organização de projetos de pesquisa diferenciados a cada curso e de intervenção resultando no que se denominou "ampliando a alfabetização". Esse conceito foi criado pela equipe pedagógica do projeto para o enriquecimento das experiências vivenciadas.

Para Schwartz (2010, p. 100), a interação na (re) construção do conhecimento e da prática pedagógica se edifica mediada pelas ações responsáveis do alfabetizador e apresenta o que se deve: 
[...] Valorizar a produção do pensamento, mas tendo clareza de que os conhecimentos socialmente construídos são necessários para servirem de base para elaborar outros conhecimentos é fundamental, porque é desta forma que o professor poderá organizar o que os alunos descobrem, criam e formulam [...].

Nessa perspectiva, compreende-se a sala de aula como um espaço onde se realizam trocas de experiências variadas. $\mathrm{O}$ alfabetizando traz consigo uma bagagem de conhecimentos que precisa ser organizada e partilhada com os demais colegas. O alfabetizador como motivador do processo da aprendizagem da leitura e da escrita deve estar sempre disponível aos alfabetizandos para estimular e incentivar o processo de construção do saber. Tal construção envolve a compreensão da dinâmica da organização social.

Pensando-se dessa forma, pressupõe-se a necessidade de organizar e selecionar um conjunto de ações, passos, condições externas e procedimentos que nortearão a metodologia mais adequada ao trabalho em sala de aula. Dessa forma percebeu-se a importância de inserir a pesquisa na formação do alfabetizador(a), pois este(a) deverá estar atento(a) aos acontecimentos da sala de aula para buscar novos temas para enriquecer o cotidiano dos alfabetizandos.

Portanto, a elaboração de projetos de pesquisa na área é importante, pois representa não só um instrumento adequado à percepção das diversas interfaces da alfabetização, mas também oportuniza o aprofundamento teórico necessário capaz de ultrapassar a mera capacitação para promover a alfabetização, proporcionando olhares variados sobre a área.

Como metodologia, privilegiou-se a escolha do método independente de trabalho que consiste em realizar tarefas dirigidas e orientadas pelo professor capacitador para que os alunos aprofundem conhecimentos de modo relativamente independente e criador, visando à execução de projetos de pesquisa ou de intervenção na área da alfabetização de jovens e adultos, portanto, é permitido ao alfabetizador criar, elaborar e apresentar as atividades pedagógicas planejadas em sala de aula e posteriormente, executar com os alunos de EJA.

Para Libâneo (1994, p. 163):

[...] trabalho independente pressupõe determinados conhecimentos, compreensão da tarefa e do seu objetivo, o domínio do método de solução, de modo que os alunos possam aplicar conhecimentos e habilidades sem a orientação direta do professor [...].
Ao apresentar e enfatizar o processo avaliativo da formação de alfabetizadores, destaca-se que a avaliação é entendida como "processo contínuo, em função do conhecimento a ser construído com os alfabetizadores, incluem-se não só habilidades e atitudes perante os trabalhos organizados na sala de aula, mas também a frequência, a pontualidade, a participação em discussões e debates, a integração nos grupos e os momentos de auto avaliação". A avaliação foi realizada durante todo o processo da capacitação.

Em particular, a avaliação dos alfabetizadores foi realizada em etapas para que fosse verificado o processo evolutivo na aquisição das habilidades da leitura e escrita. As etapas serão realizadas pelos alunos alfabetizadores durante o processo de alfabetização. A etapa final será elaborada e aplicada pela equipe pedagógica do projeto.

O processo de avaliação da atuação do aluno alfabetizador será acompanhado por meio de encontros e visitações aos locais de trabalho ou de acordo com a necessidade dos alfabetizadores em horários a serem definidos.

Finalizando, é propício mencionar o fato de que no decorrer de cada capacitação o "caderno volante" ganhou expressividade e importância do trabalho realizado pela equipe pedagógica em função de o que foi ensinado, construído e mediado com o alfabetizador.

Ao enfatizar a importância da formação de alfabetizadores para a educação de jovens e adultos, deve-se destacar, segundo Paulo Freire (1981, p. 20), que "a leitura do mundo precede a leitura da palavra e a leitura desta implica a continuidade da leitura daquele". E continua esclarecendo que por uma determinada forma de escrever, ou de reescrever, quer dizer, o que sente, pensa e age sobre os estudos, vivências e diálogos realizados durante a capacitação de alfabetizadores proposta.

Por outro lado, os depoimentos apresentados pelos alfabetizadores mereceram um destaque / reflexão do que foi realizado durante a formação dos alfabetizadores.

No que se refere ao conhecimento adquirido, assim se expressou uma alfabetizadora nesse curso: "estou muito satisfeita por ter ingressado neste curso. Gostei de ter sido a "autoestima" o primeiro tema a ser abordado. Acredito que esse é um elemento básico para todo o progresso humano desde a mais tenra idade”. (GLAUCE MAIA, 2004).

Outro depoimento deve ser destacado "o meu desejo é que todos que se engajaram neste projeto, levem o conhecimento àqueles que necessitam da nossa solidariedade" (JUNDACY, 2004). 
Em contrapartida sobre o processo de alfabetização interdisciplinar, a visão dos alfabetizadores do curso pode ser entendida no depoimento apresentado a seguir: "cada momento que passamos juntos foram perfeitos. Creio que muitos alunos como eu, puderam através de cada encontro ter novos aprendizados. Vale ressaltar que o nosso aprendizado foi além da capacitação para alfabetizar, cada experiência nos fez refletir sobre os vários problemas de nossa sociedade, com os conhecimentos relativos à alfabetização/letramento/matemática e à visão empreendedora para ajudar e orientar os alfabetizandos" (RAFAEL, 2005).

Durante o processo de mediação para orientar os alfabetizadores "geração de renda", alguns declararam durante a oficina que "é um tipo de aprendizagem que transcende as barreiras do EJA e pode ser desenvolvimento na sociedade pela comunidade sendo passado de pai para filho em uma herança familiar de saberes" (HANNA, 2013).

O entusiasmo, interesse, o reconhecimento e atuação dos alunos dos cursos numa área específica de ensino, como a que o projeto está vinculado, sempre nos surpreende. Sentimos o prazer e a alegria dos alunos em estar participando de um projeto social de grande área de atuação como esse. Observamos a participação e contribuição dos alunos da comunidade externa, expondo suas experiências e assimilando as dos colegas.

O enfrentamento dos desafios colocados pela prática de alfabetizar adultos é, para os alunos, motivo de grande satisfação e amadurecimento acadêmico. É, muitas vezes, a busca de uma realização pessoal no sentido de eles sentirem-se úteis e atuantes na sociedade.

\section{Referências}

BRASIL. Programa Alfabetização e Letramento. Fundamentos da Alfabetização: algumas reflexões. Brasília: CETEB, 2004.

DELORS, Jacques. Educação: um tesouro a descobrir. 5. ed. São Paulo: Cortez, Brasília: MEC/ UNESCO, 2001.

FREIRE, Paulo. A importância do ato de ler em três artigos que se completam. São Paulo: Cortez, 1981.

INTERNACIONAL ASSOCIATION FOR VOLUNTEER EFFORT (IAVE). Declaração Universal do Voluntariado. Paris: IAVE, 1990.

LIBÂNEO, José Carlos. Didática. São Paulo: Cortez, 1994.
SACRISTÁN, G. Mudanças Curriculares na Espanha, no Brasil e Argentina. Revista Pátio, São Paulo, ano 1, n. 0, fev. p.35-41, abr. 2009. [entrevista].

SALVIANO, Ana Regina Melo et.al UniCEUB na rede pela erradicação do Analfabetismo. Brasília: UniCEUB, 2005.

SCHWARTZ, Suzana. Alfabetização de jovens e adultos: teoria e prática. Petrópolis: Vozes, 2010. 